\title{
Erratum to: A helium gas scintillator active target for photoreaction measurements
}

The Publishers

EDP Sciences, Società Italiana di Fisica and Springer-Verlag

Original article: Eur. Phys. J. A (2015) 51: 123, DOI: 10.1140/epja/i2015-15123-y

Received: 12 October 2015

Published online: 30 October 2015 - (c) Società Italiana di Fisica / Springer-Verlag 2015

This paper has been incorrectly attributed the wrong volume number (i.e. 50 instead of 51) only in the PDF version. The metadata are correct, thus the paper is correctly listed on-line.

The Publishers regret this mistake and apologize for any inconvenience caused. 